\title{
Experimental, Thermodynamic and Kinetic Studies for the Adsorption of Phenolic Compounds Derived from Oilfield Wastewater by the Corncob Hydrochar
}

\author{
Liangcheng Xie', Kangle Ding1,2,3*, Yan Liư ${ }^{4}$, Mei Zou', Chao Han ${ }^{1}$ \\ ${ }^{1}$ College of Chemistry and Environmental Engineering, Yangtze University, Jingzhou, China \\ ${ }^{2}$ Key Laboratory of Exploration Technologies for Oil and Gas Resources (Yangtze University), Ministry of Education, Jingzhou, \\ China \\ ${ }^{3}$ Shandong Provincial Key Laboratory of Depositional Mineralization \& Sedimentary Mineral, Shandong University of Science and \\ Technology, Qingdao, China \\ ${ }^{4}$ Institute of Mud Logging Technology and Engineering, Yangtze University, Jingzhou, China \\ Email: *dingkl@yangtzeu.edu.cn
}

How to cite this paper: Xie, L.C., Ding, K.L., Liu, Y., Zou, M. and Han, C. (2019) Experimental, Thermodynamic and Kinetic Studies for the Adsorption of Phenolic Compounds Derived from Oilfield Wastewater by the Corncob Hydrochar. Open Journal of Yangtze Gas and Oil, 4, 285-300. https://doi.org/10.4236/ojogas.2019.44023

Received: May 27, 2019

Accepted: October 11, 2019

Published: October 14, 2019

Copyright $\odot 2019$ by author(s) and Scientific Research Publishing Inc. This work is licensed under the Creative Commons Attribution International License (CC BY 4.0).

http://creativecommons.org/licenses/by/4.0/ (c) (i) Open Access

\begin{abstract}
The corncob hydrochar is prepared by using a stainless autoclave at $230^{\circ} \mathrm{C}$ for $8 \mathrm{~h}$. The products are characterized by elemental analyzer, Fourier Transform infrared spectroscopy (FT-IR), X-ray diffraction (XRD) and scanning electron microscope (SEM). The effects of hydrochar dosage, $\mathrm{pH}$, adsorption time and phenol concentration on the adsorption performance of hydrochar are investigated by means of single-factor experimental analysis. Based on the experiments the adsorption thermodynamic and kinetics are tentatively discussed. The results show that abundant oxygen-containing functional groups are scattered on the surface of the corncob hydrochar. The adsorption kinetics of phenol on the hydrochar corresponds well with pseudo-second-order kinetic model. Thermodynamic studies indicate that Freundlich adsorption isotherm model is much better than Langmuir model in describing the adsorption of phenol on the corncob hydrochar at $25^{\circ} \mathrm{C}-45^{\circ} \mathrm{C}$. This study provides scientific basis for the development of cheap and efficient adsorbents for the removal of phenols derived from oilfield wastewater.
\end{abstract}

\section{Keywords}

Corncob, Hydrochar, Phenol, Adsorption, Kinetics, Thermodynamics

\section{Introduction}

A large amount of wastewater is produced during oilfield exploitation. The ef- 
fluents are mainly composed of phenols, alkanes, aromatic hydrocarbons, alcohols, aldehydes, ketones, esters, acids and nitrogen-containing compounds. Generally, phenols account for a large proportion of the total organic contaminants in the oilfield wastewater. The effective treatment of oilfield wastewater plays an important role in oilfield exploration and rational recovery of petroleum. Nowadays biochar-based adsorption technology attracts much attention in the field of wastewater treatment considering its relatively low-cost treatment and the recovery of VOCs in contrast to chemical and biological methods [1] [2] [3] [4] [5]. By adsorbing organic matter and large particles from wastewater, biochar-based adsorbents can achieve preferable removal of aqueous contaminants [6] [7] [8] [9].

Since synthesis of activated carbons is a costly process [10], in recent years much attention [11] [12] [13] [14] [15] has centered on hydrochar which is produced by hydrothermal carbonization (HTC). HTC is a thermochemical conversion process in which biomass is converted to a high carbonaceous solid product after heating for 5 to $240 \mathrm{~min}$ in an aqueous closed system at a temperature of $180^{\circ} \mathrm{C}-250^{\circ} \mathrm{C}$ and autogenous pressure of $2-6 \mathrm{MPa}$ [16]-[22]. HTC is considered as a cost-effective approach to produce hydrochar due to its ability to transform wet biomass into hydrochar without predrying [15] as well as mild conditions [23] [24].

As a waste agricultural biomass, corncob is routinely used for the production of paper pulp, livestock feed and biochemicals. However, most of corncob is burned as agricultural fuel, causing tremendous waste of resources and serious environmental pollution [15]. Hydrochars derived from corncob are prepared through hydrothermal carbonization. Phenol, which is a dominant component of organic contaminants in oilfield wastewater, is selected as the representative pollutants to evaluate the adsorbents. Specific objectives of this work are to 1) determine the feasibility of the corncob hydrochar as a phenol adsorbent; and 2) elucidate the adsorption thermodynamics and kinetics of phenol onto the corncob hydrochar.

\section{Materials and Methods}

\subsection{Instruments and Materials}

Phenol, 4-aminoantipyrine, potassium ferricyanide, hydrochloric acid, and sodium hydroxide are analytical reagents and purchased from Aladdin Industrial Corporation (Shanghai, China).

UV-visible spectrophotometer (722N), electric blast drying oven (101-1EBS), electronic balance (TP-213), high-speed Chinese medicine pulverizer (HK-08B), acidity meter (PB-10) specific surface area and porosity Analyzer (Quantasorb SI).

\subsection{Experimental}

\subsubsection{Preparation of Hydrochar}

The pristine corncob is washed with distilled water and then dried in an oven at 
$105^{\circ} \mathrm{C}$ for $5 \mathrm{~h}$. After the sample is slowly cooled to room temperature in air, it is crushed and sieved to 80 mesh. About $25 \mathrm{~g}$ of dried corncob granules are weighed and placed into a stainless-steel reaction vessel with a volume of 250 $\mathrm{mL}$. The influence of various factors such as reaction temperature, residence time e and water amount on the adsorption capacity of the prepared hydrochar is investigated by orthogonal experiment. The optimum adsorption conditions are determined as follows: $100 \mathrm{ml}$ of distilled water, $25 \mathrm{~g}$ of the raw corncob and reacting at $230^{\circ} \mathrm{C}$ for $8 \mathrm{~h}$. After the hydrothermal carbonization, the solid product is taken out, washed repeatedly with distilled water until the filtrate is nearly colorless. Afterwards, the resulting slurry is dried in an oven at the temperature of $105^{\circ} \mathrm{C}$ for $5 \mathrm{~h}$. The dried samples are ground and sieved to 80 mesh to obtain the corncob hydrochar granules.

\subsubsection{Characterization of Hydrochar}

The surface functional groups of the corncob hydrochar are identified by the Thermo Nicolet 6700 Fourier Transform Infrared Spectrometer (FTIR). The surface structures of the hydrochar samples are determined by a Gemini SEM 300 scanning electron microscope (SEM).

The element analyzer (Vario EL III, Elementar) is used to determine the contents of carbon $(\mathrm{C})$, hydrogen $(\mathrm{H})$, oxygen $(\mathrm{O})$ and nitrogen $(\mathrm{N})$ in samples. The internal crystal structure of the corncob hydrochar is analyzed by Analytical X-Ray Diffractometer (XRD).

\subsubsection{Adsorption Experiment}

$0.05 \mathrm{~g}-0.4 \mathrm{~g}$ of the corncob hydrochar granules are mixed with $50 \mathrm{~mL}$ of phenol solutions. The $\mathrm{pH}$ of the solution is adjusted to the desired value by adding concentrated $\mathrm{HCl}$ and/or $\mathrm{NaOH}$. After stirring at set temperatures for $1 \mathrm{~h}$, the mixture is filtered through a $0.45 \mu \mathrm{m}$ filter, and then the concentration of phenol in the filtrate is measured by an ultraviolet-visible spectrophotometer $(722 \mathrm{~N})$. The maximum absorption wavelength of phenol is determined by UV-visible spectrophotometer $(722 \mathrm{~N})$ as $520 \mathrm{~nm}$ by means of full wavelength scanning. A linear curve of standard phenol concentration vs. absorbance is constructed by employing a series of phenol solutions $\left(0.25,0.5,1,2,4,8\right.$ and $\left.10 \mathrm{mg} \cdot \mathrm{L}^{-1}\right)$. The standard curve is given by: $y=0.1022 x-0.0061, \mathrm{R}^{2}=0.9996$, where $\mathrm{y}$ is the absorbance and $\mathrm{x}$ is the phenol concentration.

\section{Results and Discussion}

\subsection{Characterization}

Elemental analysis of the pristine corncob and hydrochar is performed on a Vario EL III Elemental Analyzer, and the results are shown in Table 1. Compared to the raw corncob, the hydrogen, nitrogen and oxygen contents of the corncob hydrochar is reduced by $0.11 \%, 0.08 \%$ and $12.4 \%$, respectively. This indicates the occurrence of decarboxylation, and dehydration during pyrolysis and hydrothermal carbonization of biomass [25]. 
Table 1. The elemental analysis of samples.

\begin{tabular}{cccccc}
\hline Sample & $\mathrm{C}_{\mathrm{ad}}(\%)$ & $\mathrm{H}_{\mathrm{ad}}(\%)$ & $\mathrm{O}^{\mathrm{d}}(\%)$ & $\mathrm{N}_{\mathrm{ad}}(\%)$ & $\mathrm{A}_{\mathrm{ad}}(\%)$ \\
\hline Raw corncob & 46.31 & 6.13 & 46.83 & 0.62 & 0.11 \\
Corncob hydrochar & 58.95 & 6.02 & 34.43 & 0.54 & 0.06 \\
\hline
\end{tabular}

Note: ad denotes air-dried basis, d means by difference.

The carbon contents of the corncob hydrochar are increased by $12.64 \%$ in comparison with those of the pristine corncob. Notably, the carbon contents of the corncob hydrochar (58.95\%) are lower than those of some hydrochars from other raw materials such as wood and grass reported in literatures [26], but higher than those of some hydrochars from rice straw [27].

The corncob hydrochars have BET specific surface areas of $15.7858 \mathrm{~m}^{2} \cdot \mathrm{g}^{-1}$ and total pore volumes of $0.0618 \mathrm{~cm}^{3} \cdot \mathrm{g}^{-1}$. Especially, the BET surface areas of the corncob hydrochars are higher than those of some reported hydrochars produced from other raw materials such as prosopis africana shell and urban food waste [12] [13].

The FTIR spectra of the corncob hydrochar presented in Figure 1 are conducted to determine the functional groups on sample surface. The broad and strong band in the range of $3000-3600 \mathrm{~cm}^{-1}$ is assigned to the $-\mathrm{OH}$ stretching vibration in hydroxyl or carboxyl groups [28] [29] [30]. Additionally, the band at $1700 \mathrm{~cm}^{-1}$ in the FTIR spectra of the prepared hydrochars is denoted as the stretching vibration of $-\mathrm{C}=\mathrm{O}$ in carboxyl, carbonyl, quinonyl or ester groups [31]. Its relative intensity in the hydrochars is more intense than the raw corncob, indicating the generation of new oxygen functional groups on the surface of the corncob hydrochar. The peaks at 1450,1500 and $1600 \mathrm{~cm}^{-1}$ are assigned to the $-\mathrm{C}=\mathrm{C}$ vibration in aromatic ring carbon [32]. Especially, the relative intensity of the peak at $1500 \mathrm{~cm}^{-1}$ is more intense in the hydrochars than the raw corncob, indicating the occurrence of aromatization process.

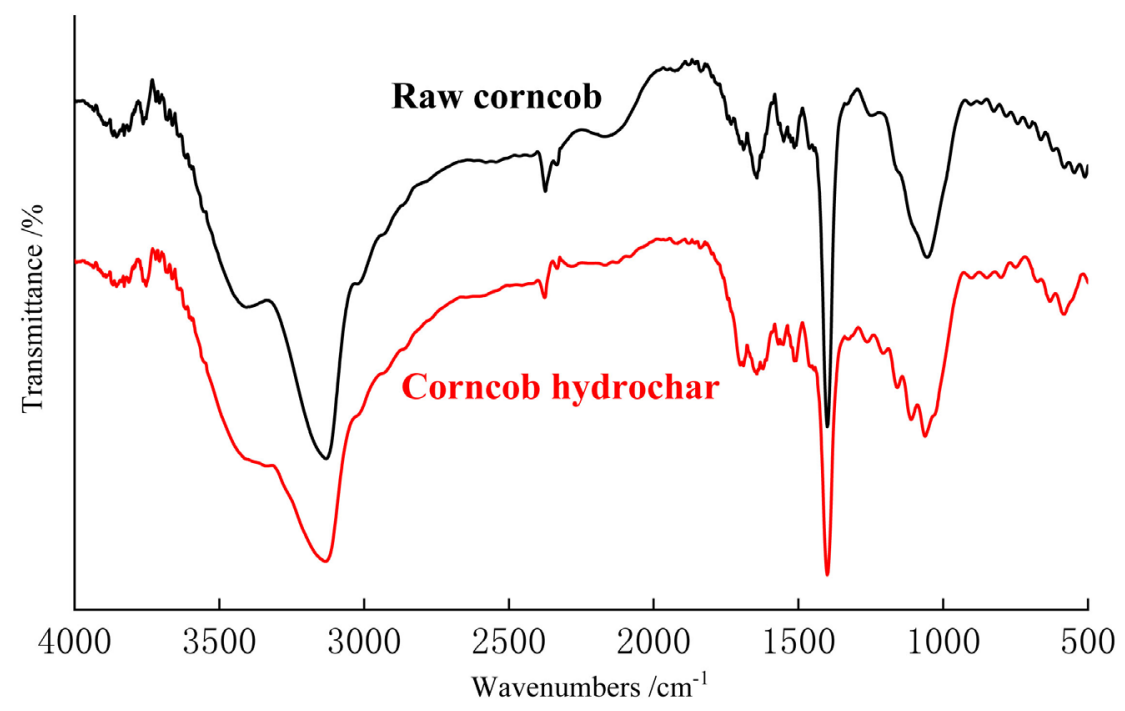

Figure 1. The FTIR spectra of the raw corncob and the representative hydrochar. 
The peak at $1400 \mathrm{~cm}^{-1}$ is associated with the in-plane bending of carbonyl (-COH) [33]. The peak at $1062 \mathrm{~cm}^{-1}$ is related to the $-\mathrm{C}-\mathrm{O}-\mathrm{R}$ stretching in ester groups and $-\mathrm{C}-\mathrm{O}$ stretching in hydroxyl groups [28]. The relative intensity of the above two peaks in the FTIR spectra of the prepared hydrochars is weaker than that of the raw corncob, implying the occurrence of dehydration during HTC [34].

The SEM images in Figure 2 are used to assess the morphological structure of the raw corncob and the prepared hydrochars. It can be seen from Figure 2(a) that the raw corncob shows clustered aggregates and few pore structures on its surface, and its morphology is dramatically changed by HTC. The sponge-like structure and the enhanced porosity are clearly developed in the representative hydrochars (Figure 2(b)), in accordance with other studies [28] [35]. The prepared hydrochars exhibits small fragments and pore structures with different diameters, possibly owing to the disintegration of the corncob matrix. The enhanced porosity of the corncob hydrochar is expected to effectively improve absorption of phenols when the hydrochar is applied for the treatment of oilfield wastewater.

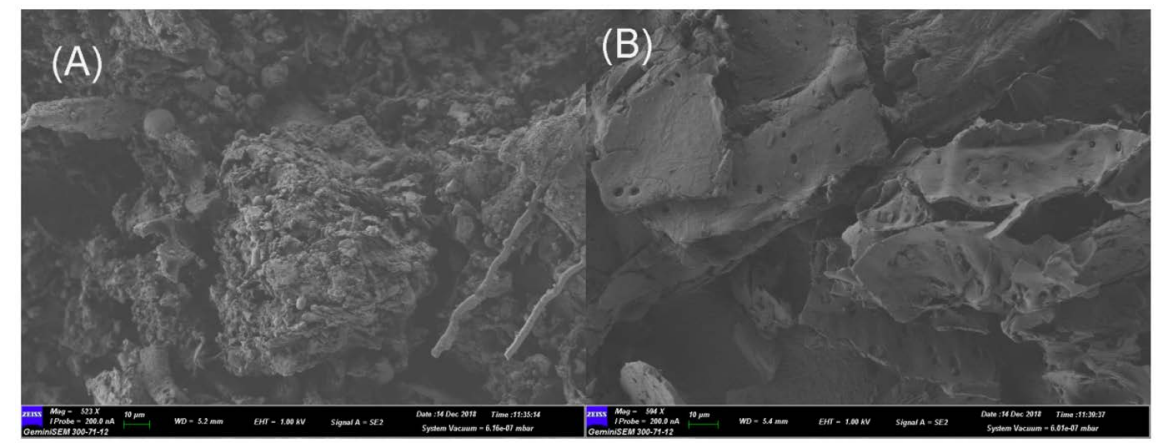

Figure 2. The SEM images of samples. (A) Corncob biomass; (B) Corncob hydrochar.

\subsection{Influence Factors of Adsorption of Phenol Bycorncob Hydrochar}

\subsubsection{Effect of Adsorbent Dosage}

The effect of the prepared hydrochar dosage on the adsorption of phenols from aqueous solution is studied at $25^{\circ} \mathrm{C}$ by using $0.05-0.4 \mathrm{~g}$ adsorbent dosage, $50 \mathrm{ml}$ of phenol solution with a concentration of $50 \mathrm{mg} / \mathrm{L}$ for $60 \mathrm{~min}$ of agitation time at $\mathrm{pH}$ of 6 . It is observed in Figure 3 that as the dose of the adsorbents increases from 0.05 to $0.15 \mathrm{~g}$, the phenol removal rate increases from $50.29 \%$ to $77.73 \%$ before equilibrium is attained. The number of sites available for the adsorption of phenols is directly proportional to the amount of adsorbent used in the measurement. Accordingly, increasing the amount of adsorbent leads to an increase in the number of active sites and therefore to an approximately linear increase in the number of phenols adsorbed by the prepared hydrochar. However, no significant change is observed after a dosage of $0.15 \mathrm{~g}$, suggesting that at this point phenols and adsorption sites have reached equilibrium. In other words, there is a threshold dosage, for which no significant increase will be observed in the up- 
take of phenols by the corncob hydrochar. As a result, $0.15 \mathrm{~g}$ of the prepared hydrochar is sufficient for the optimum removal of phenols.

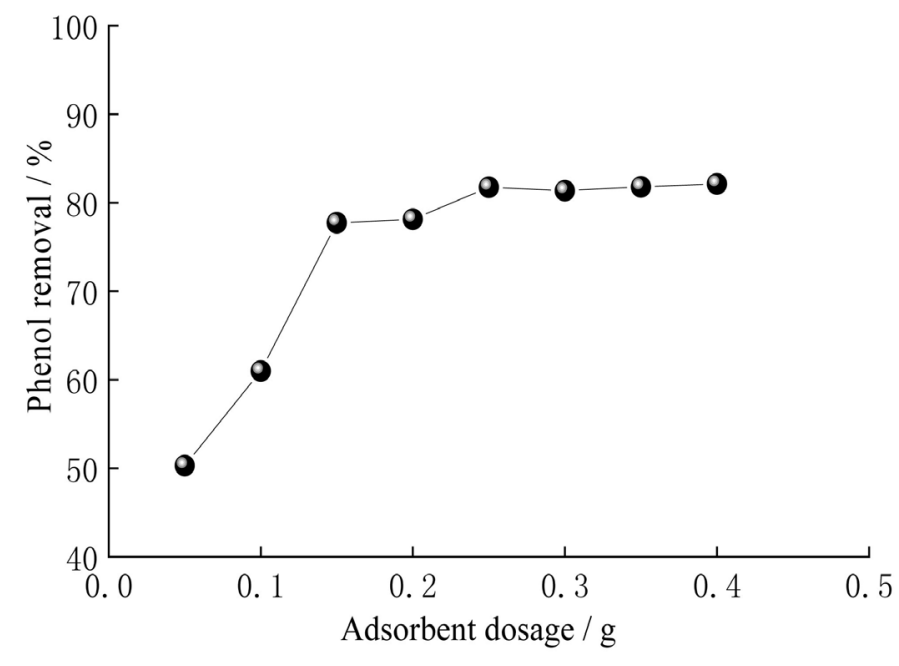

Figure 3. The effect of adsorbent dosage on phenol removal rate.

\subsubsection{Effect of Initial Phenol Concentration}

The effect of initial phenol concentration is shown in Figure 4. The experiment is performed for $60 \mathrm{~min}$ at $25^{\circ} \mathrm{C}$ by using $0.15 \mathrm{~g}$ adsorbent dosage, $50 \mathrm{ml}$ of phenol solution with concentrations of $10-100 \mathrm{mg} / \mathrm{L}$ for $60 \mathrm{~min}$ of agitation time at $\mathrm{pH}$ of 6 . There is a gradual increase in the adsorption capacity of the corncob hydrochar as the phenol concentration in the solution increases from 10 to $50 \mathrm{mg} / \mathrm{L}$. At low phenol concentration $(<50 \mathrm{mg} / \mathrm{L})$, there is a high availability of adsorption sites, therefore almost all phenols bind to the prepared hydrochar. This stage is the rapid adsorption of phenols by the prepared hydrocarbon (Figure 4). However, as the phenol concentration exceeds $50 \mathrm{mg} / \mathrm{L}$, the growth of the adsorption capacity for the corncob hydrochar slows down due to the saturation of the available adsorption sites. The interaction between phenol and the corncob hydrochar enters the slow absorption period (Figure 4).

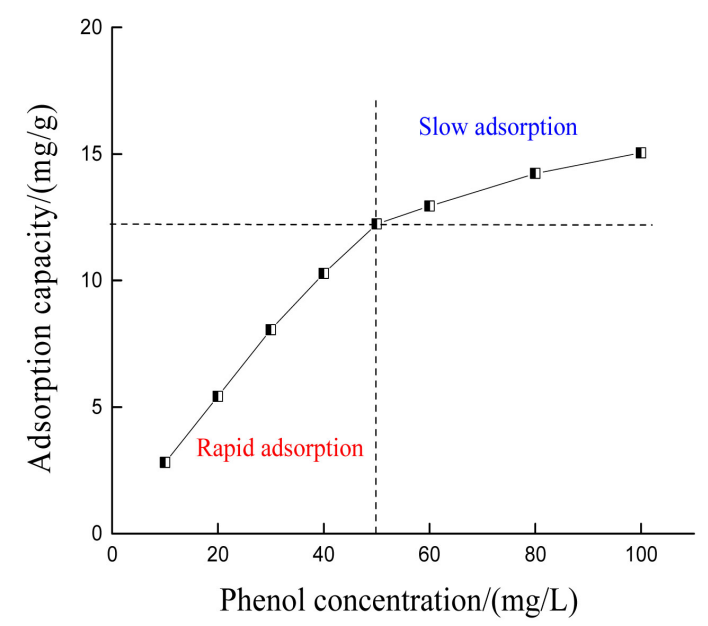

Figure 4. The effect of initial concentration of solution on adsorption capacity. 


\subsubsection{Effect of Contact Time}

The experiment is performed at $25^{\circ} \mathrm{C}$ by using $0.15 \mathrm{~g}$ adsorbent dosage, $50 \mathrm{ml}$ of phenol solution with a concentration of $50 \mathrm{mg} / \mathrm{L}$ for $60 \mathrm{~min}$ of agitation time at $\mathrm{pH}$ of 6, while the contact time is varied between 1 and $120 \mathrm{~min}$ in order to establish equilibrium. The effect of contact time on the adsorption of phenols from aqueous solution by the corncob hydrochar is shown in Figure 5. The adsorption of phenols increases rapidly within the first $30 \mathrm{~min}$, followed by a gradual increase up to $60 \mathrm{~min}$ and remains almost constant thereafter for the prepared hydrochar. Most of the phenol removal occurrs within $30 \mathrm{~min}$ with an increase of phenol removal rate from $17.35 \%$ to $66.11 \%$ and an augmentation of the adsorption capacity of the corncob hydrochar from $2.89 \mathrm{mg} \cdot \mathrm{g}^{-1}$ to $11.02 \mathrm{mg} \cdot \mathrm{g}^{-1}$. The increase in adsorption at the initial stage is due to a large number of vacant adsorption sites, which becomes saturated with time and as a result, adsorption is less efficient after $30 \mathrm{~min}$.

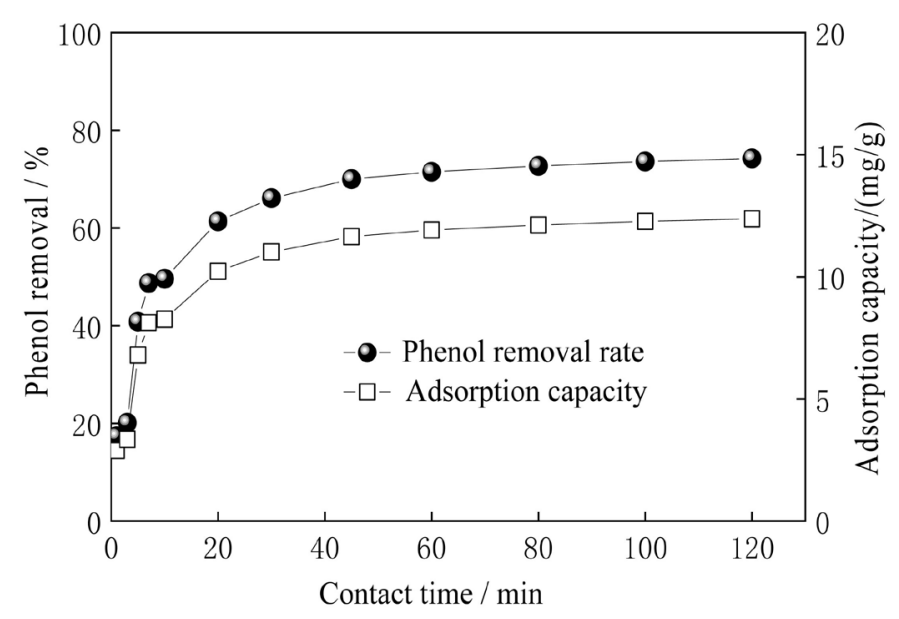

Figure 5. The effect of contact time on phenol removal rate and adsorption capacity.

\subsubsection{Effect of $\mathrm{pH}$}

The solution $\mathrm{pH}$ is an important monitoring parameter governing an adsorption process. The effect of $\mathrm{pH}$ on the phenol removal rate and adsorption capacity is studied at $25^{\circ} \mathrm{C}$ by using $0.15 \mathrm{~g}$ adsorbent dosage, $50 \mathrm{ml}$ of phenol solution with a concentration of $50 \mathrm{mg} / \mathrm{L}$ for $60 \mathrm{~min}$ of agitation time at the $\mathrm{pH}$ range of 1 12. The results of $\mathrm{pH}$ study are demonstrated in Figure 6. Figure 6 shows that the adsorption of phenol increases with the increasing of $\mathrm{pH}$. The maximum phenol removal rate $(83.25 \%)$ and the highest adsorption capacity $(13.87 \mathrm{mg} / \mathrm{g})$ are at $\mathrm{pH} 6.0$ for the prepared hydrochar. After that point the phenol removal rate as well as the adsorption capacity is found to decrease gradually. The equilibrium $\mathrm{pH} 6.0$ is considered as optimum $\mathrm{pH}$ in case of the removal of phenols for further studies. At low $\mathrm{pH}$, phenols are likely to be found as free molecules in equilibrium with protonated species in water [36], while at a $\mathrm{pH}$ above 6.0 they tend to dissociate in water to give the phenolate anion and $\mathrm{H}^{+}$due to the presence of increasing $\mathrm{OH}^{-}$groups. Two mechanisms can be used to describe adsorption onto the corncob hydrochar: the first one is coordination of the adsor- 
bate with the functional groups on the surface of the prepared hydrochar which is affected by the $\mathrm{pH}$ value of the solution, while the second one is physical adsorption relating to the surface area and porosity of the hydrochar. The coordination route should play an important role in this study as the prepared hydrochar has small surface area with low porosity. In the low $\mathrm{pH}$ range $(\mathrm{pH}<$ 4), the decreasing $\mathrm{pH}$ dramatically reduces the adsorption capacity, due to the protonation of phenols in acidic medium [37] and the presence of excess $\mathrm{H}^{+}$ions that compete with the cationic phenol molecules for adsorption sites. In the high $\mathrm{pH}$ range $(\mathrm{pH}>8)$, an increasing competition exists between the phenolate anion derived from the dissociation of phenols and the $\mathrm{OH}^{-}$in solution with the increase of $\mathrm{pH}$. Therefore, the experiments clearly show that the adsorption of phenols by the corncob hydrochar is strongly $\mathrm{pH}$ dependent, the prepared hydrochar exhibits a greater potential for the phenol adsorption at the $\mathrm{pH} 6.0$ values tested.

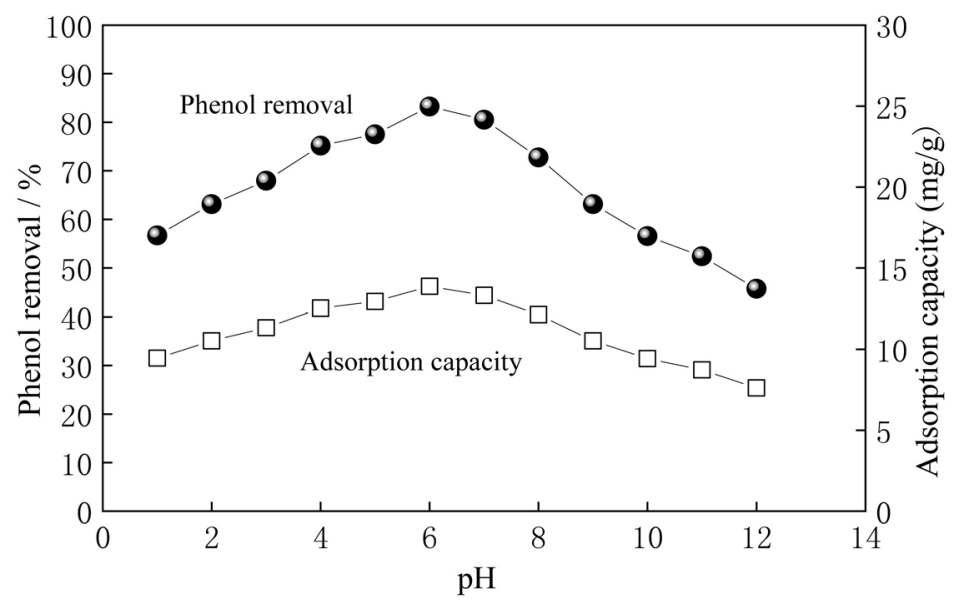

Figure 6. The effect of $\mathrm{pH}$ on phenol removal rate and adsorption capacity.

\subsection{Adsorption Kinetics}

The adsorption kinetic characteristics are important for providing valuable insights into the adsorption mechanisms [38]. The experimental kinetic data of adsorption of phenols onto the corncob hydrochar are examined by using the pseudo-first-order and pseudo-second-order equations [39].

The pseudo-first-order rate equation is expressed by

$$
q_{\mathrm{t}}=q_{\mathrm{e}}\left(1-\mathrm{e}^{-k_{1} t}\right)
$$

The pseudo-second-order rate equation is expressed by

$$
q_{\mathrm{t}}=\frac{q_{\mathrm{e}}^{2} k_{2} t}{1+q_{\mathrm{e}} k_{2} t}
$$

where $q_{\mathrm{e}}$ and $q_{\mathrm{t}}$ are the amount of phenol adsorbed per unit mass of the adsorbent $(\mathrm{mg} / \mathrm{g})$ at equilibrium and time $t$ respectively. $k_{1}\left(\mathrm{~min}^{-1}\right)$, and $k_{2}\left(\mathrm{~g} \cdot \mathrm{mg}^{-1} \cdot \mathrm{min}^{-1}\right)$ are the pseudo-first-order, and pseudo-second-order rate constant respectively. The model constants are calculated by using origin 9.1 for pseudo-first-order 
and pseudo-second-order, respectively. The results of the adsorption kinetics are presented in Table 2 and Figure 7. The correlation coefficient $\left(R^{2}\right)$ values of the pseudo-second-order are higher than that of the pseudo-first-order kinetics model; it indicates that the experimental data fit well into the pseudo-second-order model, suggesting that it can be used for the entire adsorption process [40]. The kinetic process that is fitted by the pseudo second-order kinetic model has chemisorption as the rate-determining step and involves the chemical bonding between phenols and polar functional groups on the prepared hydrochar [41].

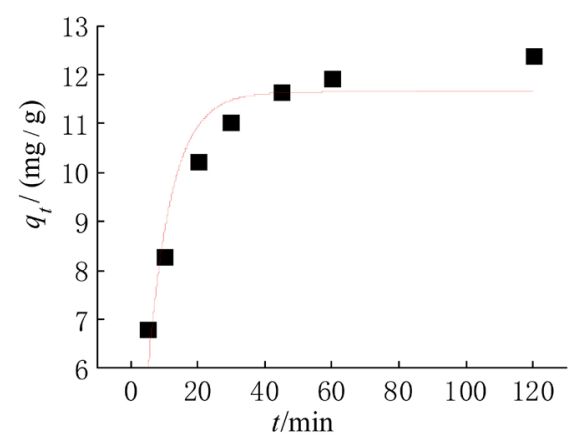

(A)

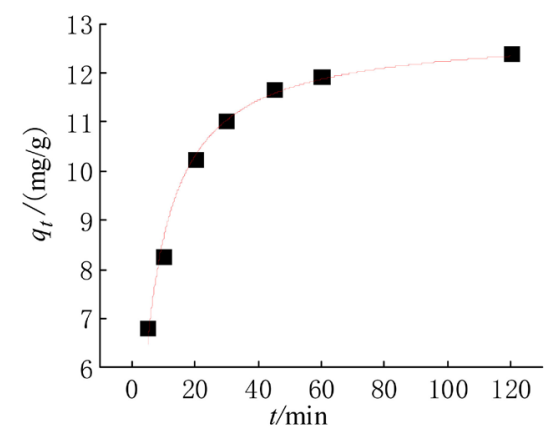

(B)

Figure 7. The kinetics of phenol adsorption by hydrochar. (A) Pseudo-first-order kinetics fitting; (B) Pseudo-second-order kinetics fitting.

Table 2. The parameters of adsorption kinetics.

\begin{tabular}{cccccc}
\hline \multicolumn{2}{c}{ Pseudo-first-order kinetic model } & \multicolumn{3}{c}{ Pseudo-second-order kinetic model } \\
\hline$\left.q_{\mathrm{e}} / \mathrm{mg}^{\mathrm{g}} \mathrm{g}^{-1}\right)$ & $k_{1} /\left(\mathrm{min}^{-1}\right)$ & $R^{2}$ & $q_{\mathrm{e}} /\left(\mathrm{mg} \cdot \mathrm{g}^{-1}\right)$ & $k \mathrm{k}_{2} /\left(\mathrm{g} \cdot \mathrm{mg}^{-1} \cdot \mathrm{min}^{-1}\right)$ & $R^{2}$ \\
\hline 11.64 & 0.140 & 0.904 & 12.84 & 0.015 & 0.991 \\
\hline
\end{tabular}

A detailed understanding of adsorption mechanisms facilitates a determination of the rate-limiting step. This information can then be used to optimize the design of adsorbents and adsorption conditions. The overall rate of adsorption can be described by the following three steps [42]: 1) film or surface diffusion where the sorbate is transported from the bulk solution to the external surface of sorbent, 2) intraparticle or pore diffusion, where sorbate molecules move into the interior of sorbent particles, and 3) adsorption on the interior sites of the 
sorbent. Since the adsorption step is very rapid, it is assumed that it does not influence the overall kinetics. The overall rate of adsorption process, therefore, will be controlled by either surface diffusion or intraparticle diffusion.

\subsection{Adsorption Isotherms}

The sorption data of phenols are correlated with Langmuir and Freundlich models (Equation (3) and Equation (4)).

Langmuir equation:

$$
\frac{C_{\mathrm{e}}}{q_{\mathrm{e}}}=\frac{C_{\mathrm{e}}}{q_{\max }}+\frac{1}{K_{\mathrm{L}} \times q_{\max }}
$$

Freundlich equation:

$$
\lg q_{\mathrm{e}}=\frac{\lg C_{\mathrm{e}}}{n}+\lg K_{\mathrm{F}}
$$

where $C_{\mathrm{e}}$ is the equilibrium concentration of phenol in the water $(\mathrm{mg} / \mathrm{L}), q_{\mathrm{e}}$ is the amount of phenol adsorbed per unit mass of the adsorbent at equilibrium state $(\mathrm{mg} / \mathrm{g}), q_{\max }$ is the maximum adsorption capacity $\left(\mathrm{mg}^{-1} \mathrm{~g}^{-1}\right) . K_{\mathrm{L}}$ and $K_{\mathrm{F}}$ are the coefficient of the adsorption rate $\left(\mathrm{L} \cdot \mathrm{mg}^{-1} \cdot \mathrm{min}^{-1}\right), n$ is the intensity of the adsorption constant. Figure 8 shows the fitting curves of the Langmuir and Freundlich isotherms. A summary of the theoretical parameters and the corresponding $\mathrm{R}^{2}$ values are shown in Table 3 . The $\mathrm{R}^{2}$ values for the adsorption of phenol onto the prepared hydrochar are higher for the Freundlich model, implying that the adsorption data fit the Freundlich model better than the Langmuir model. Normally, in consideration of the heterogeneity of the hydrochars in physical-chemical properties (e.g., surface function groups and elemental compositions), it is reasonable to expect Freundlich model to give a better description for the isotherm curve. Constant $n$ in Freundlich model gives a measure of favorability of adsorption: favorable $(1<n<10)$, irreversible $(n=1)$, unfavorable $(n<$ 1) [13]. In the current investigation, the values of $n$ suggest that the phenol uptake by the prepared hydrochar can be considered to be a favorable adsorption process. Additionally, an increase in the value of $\mathrm{n}$ with the increasing of temperature reflects stronger interaction between phenol and the corncob hydrochar at higher temperatures. For the Freundlich constant, $K_{\mathrm{F}}$, which is related to the adsorption capacity, increases with temperature, indicating that the adsorption process is endothermic.

Table 3. The Langmuir and Freundlich isotherm parameters for the adsorption of phenol onto the corncob hydrochar.

\begin{tabular}{ccccccc}
\hline & \multicolumn{3}{c}{ Langmuir } & \multicolumn{3}{c}{ Freundlich } \\
\cline { 2 - 7 } Temperature $/{ }^{\circ} \mathrm{C}$ & $K_{\mathrm{L}}$ & $q_{\max }$ & $R^{2}$ & $K_{\mathrm{F}}$ & $n$ & $R^{2}$ \\
\hline 25 & 0.0171 & 45.63 & 0.9668 & 3.2771 & 2.139 & 0.9906 \\
35 & 0.0444 & 50.80 & 0.8874 & 4.4728 & 2.159 & 0.9934 \\
45 & 0.0256 & 68.57 & 0.9002 & 5.7544 & 2.187 & 0.9835 \\
\hline
\end{tabular}




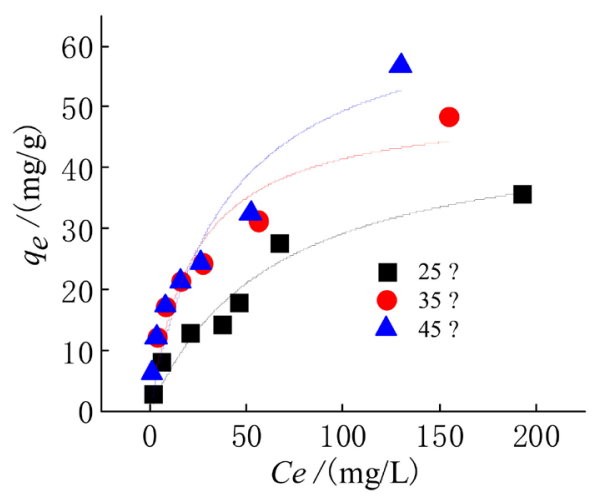

(A)

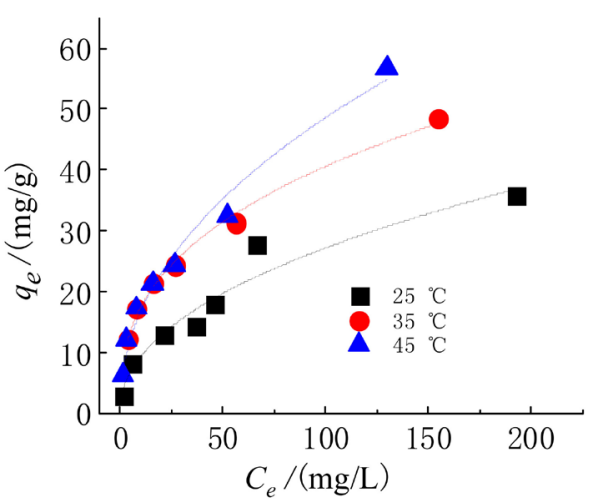

(B)

Figure 8. The isothermal adsorption of phenol on the corncob hydrochar. (A) Langmuir model; (B) Freundlich model.

\subsection{Thermodynamic Studies}

When the thermodynamic parameters are properly assessed, they can provide in-depth information regarding the inherent energy and structural changes after adsorption. Thermodynamically, in an isolated system, energy cannot be gained or lost; the entropy change is the driving force. In the practice of environmental engineering, both energy and entropy factors should be considered for determining the processes that occur spontaneously. The thermodynamic parameters, the Gibbs free energy change of adsorption $\Delta G^{\circ}\left(\mathrm{kJ} \cdot \mathrm{mol}^{-1}\right)$, enthalpy $\left(\Delta H^{\circ}\right.$, $\left.\mathrm{kJ} \cdot \mathrm{mol}^{-1}\right)$, and entropy $\left(\Delta S^{\circ}, \mathrm{J} \cdot \mathrm{mol}^{-1} \cdot \mathrm{K}^{-1}\right)$ for the adsorption of phenol onto the prepared hydrochar are calculated by using the following equations:

$$
\Delta G^{\circ}=-R T \ln K_{\mathrm{F}}
$$

where $R$ is the universal gas constant $\left(8.314 \mathrm{~J} \cdot \mathrm{mol}^{-1} \cdot \mathrm{K}^{-1}\right), T$ is the absolute temperature and $K_{\mathrm{F}}$ is the Freundlich constant. The enthalpy $\left(\Delta H^{\circ}\right)$ and entropy $\left(\Delta S^{\circ}\right)$ values are estimated from the following equations:

$$
\Delta G^{\circ}=\Delta H^{\circ}-T \Delta S^{\circ}
$$

The values of $\Delta G^{\circ}$ are calculated from Equation (5). Reciprocal of temperature $T$ is plotted against $\Delta G^{\circ}$, which is found to be a straight line (Figure 9). The values of $\Delta H^{\circ}$ and $\Delta S^{\circ}$ are evaluated from the slope and intercept of the line in Figure 9. The Gibbs free energy $\left(\Delta G^{\circ}\right)$, enthalpy $\left(\Delta H^{\circ}\right)$ and entropy $\left(\Delta S^{\circ}\right)$ values 
for the adsorption of phenol onto the corncob hydrochar are presented in Table 4. The negative values of $\Delta G^{\circ}$ denote that the adsorption of phenol onto the prepared hydrochar is spontaneous and thus thermodynamically favorable. The magnitude of $\Delta G^{\circ}$ also increases with the increase of the temperature, which indicates that the adsorption is more favorable at higher temperatures. The value of $\Delta H^{\circ}$ is positive, indicating the endothermic nature of the adsorption of phenol onto the corncob hydrochar at the temperature range of $298-318 \mathrm{~K}$. One possible explanation of endothermicity of the enthalpy of adsorption is due to the reason that hydrogen bonds are formed between phenol and water molecules [43]. Phenols would not be adsorbed by hydrochars until the hydrogen bonds are destroyed. This rupture of hydrogen bonds between phenol and water molecules obviously requires energy. It is reasonably assumed that this energy of hydrogen-bond breaking exceeds the exothermicity of the phenol attaching to the surface of the corncob hydrochar. The positive values of $\Delta S^{\circ}$ indicate the increase in randomness at the interface of the solid/liquid during the adsorption process, and shows the good affinity of the adsorbents for the adsorbed species. It should be noted that a chemisorbed layer could be followed by the physically adsorbed layer which may not be excluded in this study.

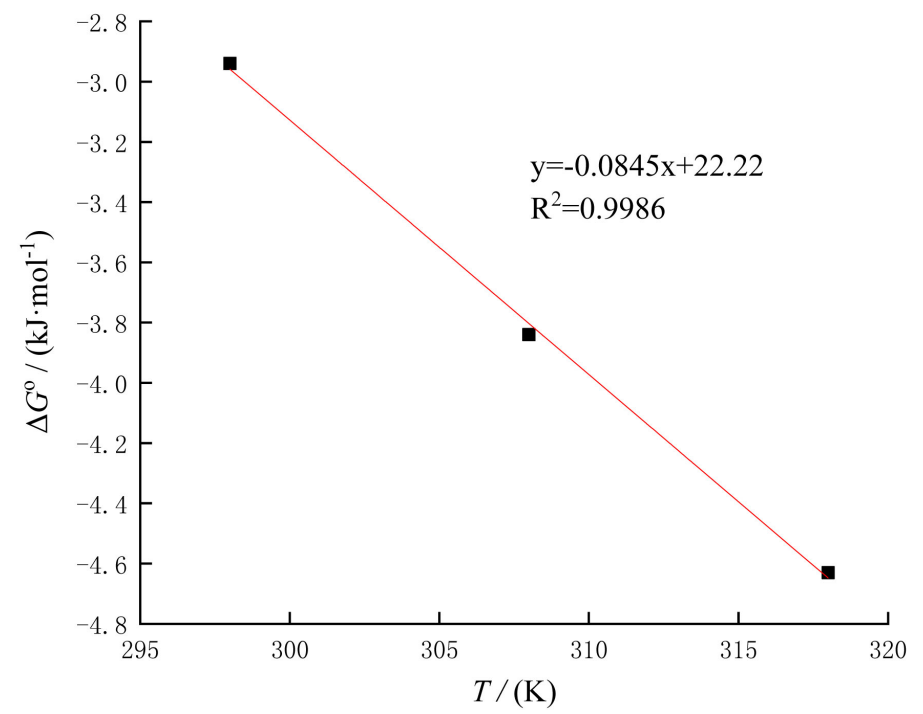

Figure 9. The plot of $\Delta G^{\mathrm{o}}$ versus $T$.

Table 4. The thermodynamic parameters for phenol adsorption onto the corncob hydrochar.

\begin{tabular}{cccc}
\hline Temperature $(\mathrm{K})$ & $\Delta G^{\circ}\left(\mathrm{kJ} \cdot \mathrm{mol}^{-1}\right)$ & $\Delta H^{\circ}\left(\mathrm{kJ} \cdot \mathrm{mol}^{-1}\right)$ & $\Delta S^{\circ}\left(\mathrm{J} \cdot \mathrm{mol}^{-1} \cdot \mathrm{K}^{-1}\right)$ \\
\hline 298 & -2.94 & & \\
308 & -3.84 & 22.22 & 84.50 \\
318 & -4.63 & & \\
\hline
\end{tabular}

\section{Conclusion}

In this study, experiments are performed to evaluate the use of hydrochars pre- 
pared from the hydrothermal carbonization of corncob as an adsorbent for phenols in aqueous solution. It is found that the prepared hydrochars are rich in oxygen containing functional groups. The phenol removal rate and/or adsorption capacity are highly dependent on the $\mathrm{pH}$ of the aqueous solution, the amount of adsorbent used, initial phenol concentration as well as the contact time. Thermodynamic analysis shows that the adsorption process is endothermic and spontaneous in nature. The kinetics of the adsorption processes follow a pseudo-second-order rate law with the adsorption data being described by the Freundlich isotherm model. The results suggest that low cost corncob hydrochars obtained from an abundant natural resource may be used as effective adsorbents for the removal of phenols from oilfield wastewater.

\section{Acknowledgements}

We gratefully acknowledge financial support by the National Natural Science Foundation of China (No. 41472095), the Open Fund of Key Laboratory of Exploration Technologies for Oil and Gas Resources (Yangtze University), Ministry of Education (No. K2018-05) and the Foundation of Shandong Provincial Key Laboratory of Depositional Mineralization and Sedimentary Minerals, Shandong University of Science and Technology (Grant No. DMSM2018041).

\section{Conflicts of Interest}

The authors declare no conflicts of interest regarding the publication of this paper.

\section{References}

[1] Tefera, D.T., Hashisho, Z., Philips, J.H., Anderson, J.E. and Nichols, M. (2014) Modeling Competitive Adsorption of Mixtures of Volatile Organic Compounds in a Fixed-Bed of Beaded Activated Carbon. Environmental Science \& Technology, 48, 5108-5117. https://doi.org/10.1021/es404667f

[2] Zhang, X., Gao, B., Creamer, A.E., Cao, C. and Li, Y. (2017) Adsorption of VOCs onto Engineered Carbon Materials: A Review. Journal of Hazardous Materials, 338, 102-123. https://doi.org/10.1016/j.jhazmat.2017.05.013

[3] Zhang, X., Gao, B., Fang, J., Zou, W., Dong, L., Cao, C., Zhang, J., Li, Y. and Wang, H. (2019) Chemically Activated Hydrochar as an Effective Adsorbent for Volatile Organic Compounds (VOCs). Chemosphere, 218, 680-686. https://doi.org/10.1016/j.chemosphere.2018.11.144

[4] Dutta, T., Kim, T., Vellingiri, K., Tsang, D.C.W., Shon, J., Kim, K.-H. and Kumar, S. (2019) Recycling and Regeneration of Carbonaceous and Porous Materials through Thermal or Solvent Treatment. Chemical Engineering Journal, 364, 514-529. https://doi.org/10.1016/j.cej.2019.01.049

[5] Zhang, Z., Zhu, Z., Shen, B. and Liu, L. (2019). Insights into Biochar and Hydrochar Production and Applications: A Review. Energy. 171, 581-598. https://doi.org/10.1016/j.energy.2019.01.035

[6] Qian, K., Kumar, A., Zhang, H., Bellmer, D. and Huhnke, R. (2015) Recent Advances in Utilization of Biochar. Renewable and Sustainable Energy Reviews, 42, 1055-1064. https://doi.org/10.1016/j.rser.2014.10.074 
[7] Tan, X., Liu, Y., Gu, Y., Xu, Y., Zeng, G., Hu, X., Liu, S., Wang, X., Liu, S. and Li, J. (2016) Biochar-Based Nano-Composites for the Decontamination of Wastewater: A Review. Bioresource Technology, 212, 318-333. https://doi.org/10.1016/j.biortech.2016.04.093

[8] Wang, B., Wang, Z., Jiang, Y., Tan, G., Xu, N. and Xu, Y. (2017) Enhanced Power Generation and Wastewater Treatment in Sustainable Biochar Electrodes Based Bioelectrochemical System. Bioresource Technology, 241, 841-848. https://doi.org/10.1016/j.biortech.2017.05.155

[9] Tang, L., Yu, J., Pang, Y., Zeng, G., Deng, Y., Wang, J., Ren, X., Ye, S., Peng, B. and Feng, H. (2018) Sustainable Efficient Adsorbent: Alkali-Acid Modified Magnetic Biochar Derived from Sewage Sludge for Aqueous Organic Contaminant Removal. Chemical Engineering Journal, 336, 160-169. https://doi.org/10.1016/j.cej.2017.11.048

[10] Zhao, P., Shen, Y., Ge, S. and Yoshikawa, K. (2014) Energy Recycling from Sewage Sludge by Producing Solid Biofuel with Hydrothermal Carbonization. Energy Conversion and Management, 78, 815-821. https://doi.org/10.1016/j.enconman.2013.11.026

[11] Liu, Z., Zhang, F.-S. and Wu, J. (2010) Characterization and Application of Chars Produced from Pinewood Pyrolysis and Hydrothermal Treatment. Fuel, 89, 510-514. https://doi.org/10.1016/j.fuel.2009.08.042

[12] Elaigwu, S.E., Rocher, V., Kyriakou, G. and Greenway, G.M. (2014) Removal of $\mathrm{Pb}^{2+}$ and $\mathrm{Cd}^{2+}$ from Aqueous Solution Using Chars from Pyrolysis and Microwave-Assisted Hydrothermal Carbonization of Prosopis africana Shell. Journal of Industrial and Engineering Chemistry, 20, 3467-3473.

https://doi.org/10.1016/j.jiec.2013.12.036

[13] Parshetti, G.K., Chowdhury, S. and Balasubramanian, R. (2014) Hydrothermal Conversion of Urban Food Waste to Chars for Removal of Textile Dyes from Contaminated Waters. Bioresource Technology, 161, 310-319. https://doi.org/10.1016/j.biortech.2014.03.087

[14] Jain, A., Balasubramanian, R. and Srinivasan, M.P. (2016) Hydrothermal Conversion of Biomass Waste to Activated Carbon with High Porosity: A Review. Chemical Engineering Journal, 283, 789-805. https://doi.org/10.1016/j.cej.2015.08.014

[15] Wang, T., Zhai, Y., Zhu, Y., Li, C. and Zeng, G. (2018) A Review of the Hydrothermal Carbonization of Biomass Waste for Hydrochar Formation: Process Conditions, Fundamentals, and Physicochemical Properties. Renewable and Sustainable Energy Reviews, 90, 223-247. https://doi.org/10.1016/j.rser.2018.03.071

[16] Funke, A. and Ziegler, F. (2010) Hydrothermal Carbonization of Biomass: A Summary and Discussion of Chemical Mechanisms for Process Engineering. Biofuels, Bioproducts and Biorefining, 4, 160-177. https://doi.org/10.1002/bbb.198

[17] Libra, J.A., Ro, K.S., Kammann, C., Funke, A., Berge, N.D., Neubauer, Y., Titirici, M.-M., Fühner, C., Bens, O., Kern, J. and Emmerich, K.-H. (2011) Hydrothermal Carbonization of Biomass Residuals: A Comparative Review of the Chemistry, Processes and Applications of Wet and Dry Pyrolysis. Biofuels, 2, 71-106. https://doi.org/10.4155/bfs.10.81

[18] Hoekman, S.K., Broch, A., Robbins, C., Zielinska, B. and Felix, L. (2012) Hydrothermal Carbonization (HTC) of Selected Woody and Herbaceous Biomass Feedstocks. Biomass Conversion and Biorefinery, 3, 113-126. https://doi.org/10.1007/s13399-012-0066-y

[19] Wiedner, K., Naisse, C., Rumpel, C., Pozzi, A., Wieczorek, P. and Glaser, B. (2013) 
Chemical Modification of Biomass Residues during Hydrothermal Carbonization-What Makes the Difference, Temperature or Feedstock? Organic Geochemistry, 54, 91-100. https://doi.org/10.1016/j.orggeochem.2012.10.006

[20] Xu, Q., Qian, Q., Quek, A., Ai, N., Zeng, G. and Wang, J. (2013) Hydrothermal Carbonization of Macroalgae and the Effects of Experimental Parameters on the Properties of Hydrochars. ACS Sustainable Chemistry \& Engineering, 1, 1092-1101. https://doi.org/10.1021/sc400118f

[21] Kambo, H.S. and Dutta, A. (2015) A Comparative Review of Biochar and Hydrochar in Terms of Production, Physico-Chemical Properties and Applications. Renewable and Sustainable Energy Reviews, 45, 359-378. https://doi.org/10.1016/j.rser.2015.01.050

[22] Bach, Q.-V. andSkreiberg, Ø. (2016) Upgrading Biomass Fuels via Wet Torrefaction: A Review and Comparison with Dry Torrefaction. Renewable and Sustainable Energy Reviews, 54, 665-677. https://doi.org/10.1016/j.rser.2015.10.014

[23] Guo, S., Dong, X., Zhu, C., Han, Y., Ma, F. and Wu, T. (2017) Pyrolysis Behaviors and Thermodynamics Properties of Hydrochar from Bamboo (Phyllostac hysheterocycla cv. Pubescens) Shoot Shell. Bioresource Technology, 233, 92-98. https://doi.org/10.1016/j.biortech.2017.02.072

[24] Fang, J., Zhan, L., Ok, Y.S. and Gao, B. (2018) Minireview of Potential Applications of Hydrochar Derived from Hydrothermal Carbonization of Biomass. Journal of Industrial and Engineering Chemistry, 57, 15-21. https://doi.org/10.1016/j.jiec.2017.08.026

[25] Ghanim, B.M., Pandey, D.S., Kwapinski, W. and Leahy, J.J. (2016) Hydrothermal Carbonisation of Poultry Litter: Effects of Treatment Temperature and Residence Time on Yields and Chemical Properties of Hydrochars. Bioresource Technology, 216, 373-380. https://doi.org/10.1016/j.biortech.2016.05.087

[26] Reza, M.T., Andert, J., Wirth, B., Busch, D., Pielert, J., Lynam, J.G. and Mumme, J. (2014) Hydrothermal Carbonization of Biomass for Energy and Crop Production. Applied Bioenergy, 1, 11-29. https://doi.org/10.2478/apbi-2014-0001

[27] Li, Y., Tsend, N., Li, T., Liu, H., Yang, R., Gai, X., Wang, H. and Shan, S. (2019) Microwave Assisted Hydrothermal Preparation of Rice Straw Hydrochars for Adsorption of Organics and Heavy Metals. Bioresource Technology, 273, 136-143. https://doi.org/10.1016/j.biortech.2018.10.056

[28] He, C., Zhao, J., Yang, Y. and Wang, J.-Y. (2016) Multiscale Characteristics Dynamics of Hydrochar from Hydrothermal Conversion of Sewage Sludge under Suband Near-Critical Water. Bioresource Technology, 211, 486-493. https://doi.org/10.1016/j.biortech.2016.03.110

[29] Muhammad, S.U.R., Kim, I., Rashid, N., Adeel Umer, M., Sajid, M. and Han, J.I. (2016) Adsorption of Brilliant Green Dye on Biochar Prepared from Lignocellulosic Bioethanol Plant Waste. CLEAN \& Soil, Air, Water, 44, 55-62. https://doi.org/10.1002/clen.201300954

[30] Saha, N., Saba, A. and Reza, M.T. (2019) Effect of Hydrothermal Carbonization Temperature on $\mathrm{pH}$, Dissociation Constants, and Acidic Functional Groups on Hydrochar from Cellulose and Wood. Journal of Analytical and Applied Pyrolysis. 137, 138-145. https://doi.org/10.1016/j.jaap.2018.11.018

[31] He, C., Giannis, A. and Wang, J.-Y. (2013) Conversion of Sewage Sludge to Clean Solid Fuel Using Hydrothermal Carbonization: Hydrochar Fuel Characteristics and Combustion Behavior. Applied Energy, 111, 257-266. https://doi.org/10.1016/j.apenergy.2013.04.084 
[32] Chen, X., Ma, X., Peng, X., Lin, Y. and Yao, Z. (2018) Conversion of Sweet Potato Waste to Solid Fuel via Hydrothermal Carbonization. Bioresource Technology, 249, 900-907. https://doi.org/10.1016/j.biortech.2017.10.096

[33] Yuan, J.-H., Xu, R.-K. and Zhang, H. (2011) The Forms of Alkalis in the Biochar Produced from Crop Residues at Different Temperatures. Bioresource Technology, 102, 3488-3497. https://doi.org/10.1016/j.biortech.2010.11.018

[34] Unur, E. (2013) Functional Nanoporous Carbons from Hydrothermally Treated Biomass for Environmental Purification. Microporous and Mesoporous Materials, 168, 92-101. https://doi.org/10.1016/j.micromeso.2012.09.027

[35] Lang, Q., Zhang, B., Liu, Z., Jiao, W., Xia, Y., Chen, Z., Li, D., Ma, J. and Gai, C. (2019) Properties of Hydrochars Derived from Swine Manure by CaO Assisted Hydrothermal Carbonization. Journal of Environmental Management, 233, 440-446. https://doi.org/10.1016/j.jenvman.2018.12.072

[36] Oikawa, A., Abe, H., Mikami, N. and Ito, M. (1983) Solvated Phenol Studied by Supersonic Jet Spectroscopy. The Journal of Physical Chemistry, 87, 5083-5090. https://doi.org/10.1021/j150643a009

[37] Solcà, N. and Dopfer, O. (2001) Protonation of Aromatic Molecules: Competition between Ring and Oxygen Protonation of Phenol (Ph) Revealed by IR Spectra of $\mathrm{PhH}^{+}-\mathrm{Ar}_{\mathrm{n}}$. Chemical Physics Letters, 342, 191-199. https://doi.org/10.1016/S0009-2614(01)00556-5

[38] Wang, Y., Shen, Z., Niu, J. and Liu, R. (2009) Adsorption of Phosphorus on Sediments from the Three-Gorges Reservoir (China) and the Relation with Sediment Compositions. Journal of Hazardous Materials, 162, 92-98. https://doi.org/10.1016/j.jhazmat.2008.05.013

[39] Olgun, A. and Atar, N. (2012). Equilibrium, Thermodynamic and Kinetic Studies for the Adsorption of Lead (II) and Nickel (II) onto Clay Mixture Containing Boron Impurity. Journal of Industrial and Engineering Chemistry, 18, 1751-1757. https://doi.org/10.1016/j.jiec.2012.03.020

[40] Chen, X., Chen, G., Chen, L., Chen, Y., Lehmann, J., McBride, M.B. and Hay, A.G. (2011) Adsorption of Copper and Zinc by Biochars Produced from Pyrolysis of Hardwood and Corn Straw in Aqueous Solution. Bioresource Technology, 102, 8877-8884. https://doi.org/10.1016/j.biortech.2011.06.078

[41] Ho, Y.S., Ng, J.C.Y. and McKay, G. (2001) Removal of Lead(II) from Effluents by Sorption on Peat Using Second-Order Kinetics. Separation Science and Technology, 36, 241-261. https://doi.org/10.1081/SS-100001077

[42] Chingombe, P., Saha, B. and Wakeman, R.J. (2006) Sorption of Atrazine on Conventional and Surface Modified Activated Carbons. Journal of Colloid \& Interface Science, 302, 408-416. https://doi.org/10.1016/j.jcis.2006.06.065

[43] Wang, S., Hao, C., Wang, D., Dong, H. and Qiu, J. (2011) Hydrogen Bonding Dynamics of Phenol- $\left(\mathrm{H}_{2} \mathrm{O}\right)_{2}$ Cluster in the Electronic Excited State: A DFT/TDDFT Study. Journal of the Korean Chemical Society, 55, 385-391. https://doi.org/10.5012/jkcs.2011.55.3.385 